\title{
50 Social Interaction, Co-Worker Altruism, and Incentives
}

\author{
Robert Dur* \\ Joeri Sol
}

Department of Economics, Erasmus University Rotterdam, and Tinbergen Institute.

*CESifo, and IZA. 


\section{Tinbergen Institute}

The Tinbergen Institute is the institute for economic research of the Erasmus Universiteit Rotterdam, Universiteit van Amsterdam, and Vrije Universiteit Amsterdam.

Tinbergen Institute Amsterdam

Roetersstraat 31

1018 WB Amsterdam

The Netherlands

Tel.: +31(0)205513500

Fax: $+31(0) 205513555$

Tinbergen Institute Rotterdam

Burg. Oudlaan 50

3062 PA Rotterdam

The Netherlands

Tel.: + $31(0) 104088900$

Fax: $+31(0) 104089031$

Most TI discussion papers can be downloaded at http://www.tinbergen.nl. 


\title{
Social Interaction, Co-Worker Altruism, and Incentives*
}

\author{
Robert Dur ${ }^{\dagger}$ and Joeri Sol ${ }^{\ddagger}$
}

August 3, 2009

\begin{abstract}
Social interaction with colleagues is an important job attribute for many workers. To attract and retain workers, managers therefore need to think about how to create and preserve high-quality co-worker relationships. This paper develops a principal-multi-agent model where agents do not only engage in productive activities, but also in social interaction with their colleagues, which in turn creates co-worker altruism. We study how financial incentives for productive activities can improve or damage the work climate. We show that both team incentives and relative incentives can help to create a good work climate. We discuss some empirical evidence supporting these predictions.
\end{abstract}

JEL-codes: D86, J41, M50.

Keywords: social interaction, altruism, incentive contracts, coworker satisfaction.

${ }^{*}$ We gratefully acknowledge comments and suggestions by Maxim Frolov, Vladimir Karamychev, Veikko Thiele, Mirco Tonin, seminar audiences at Universitat Autonoma de Barcelona, Erasmus University Rotterdam, and the University of Zürich, and participants to the Conference on 'Tournaments, Contests and Relative Performance Evaluation' at North Carolina State University, the CESifo Area Conference on Employment and Social Protection 2008 in Munich, the EBIM Workshop 2008 in Bielefeld, the NAKE Day 2008 in Utrecht, the TI Conference on 'Human Relations, Reciprocity, and Incentives in the Workplace' in Rotterdam, the IMEBE 2009 in Granada, and the 2009 International Conference on Happiness and Relational Goods in Venice.

${ }^{\dagger}$ Department of Economics, Erasmus University Rotterdam, Tinbergen Institute, CESifo, and IZA. E-mail: dur@ese.eur.nl

${ }^{\ddagger}$ Tinbergen Institute, Erasmus University Rotterdam. E-mail: jsol@ese.eur.nl. 


\section{Introduction}

Social interaction with colleagues is a highly valued job aspect for many workers. Research in psychology, sociology, and management shows that receiving affective support from colleagues and having good interpersonal relationships at work are positively associated with job satisfaction, job involvement, and organizational commitment, and negatively with employee stress and absenteeism (see among others Price and Mueller 1981, Riordan and Griffeth 1995, Hodson 1997, Ducharme and Martin 2000, Nielsen et al. 2000, Morrison 2004, and Wagner and Harter 2006). Moreover, turnover intentions and actual turnover tend to be lower when workers experience social support from co-workers (Price and Mueller 1981, Riordan and Griffeth 1995, Nielsen et al. 2000, Morrison 2004, and Mossholder et al. 2005). Social interaction with colleagues is also one of the most missed job aspects under retired workers in Australia (Shacklock 2005) - and it is one of the main drivers of job search among Dutch unemployed (Echtelt and Hoff 2008). Lastly, using time-use data for France and the US, Krueger and Schkade (2007) show that workers who are in jobs that entail more frequent interactions with co-workers are more satisfied with their jobs and in a better mood during work time.

These findings have a clear managerial implication: In their struggle to attract and retain workers, managers should strive to create and maintain high-quality co-worker relationships. This view is confirmed by managers. Berman et al. (2002) report the results of a survey among managers in the US and show that more than $85 \%$ of managers approve or strongly approve of workplace friendships. A similar percentage reports that their organization actively encourages workplace friendship. An obvious and widely used means of doing so is to facilitate social interaction among co-workers through e.g. creating coffee corners or a nice canteen, having Friday-afternoon drinks, or organizing after-work social events (Cohen and Prusak 2001). However, as we shall see, when a company's workplace policies are limited to facilitating social interaction, typically too little social interaction takes place, implying lower than first-best profits.

This paper studies an alternative, complementary way to promote coworker relationships: fine-tuning workers' financial incentives. We develop a principal-multi-agent model in which workers do not only engage in productive activities, but also in social interaction with their colleagues. Workers' productive activities are, for convenience, assumed to be fully contractible. Social interaction, however, is not contractible at all. We model social inter- 
action as an exchange of 'attention' between workers. Attention may include showing interest in a colleague's personal life, offering a drink after working hours, or any other kind gestures. While receipt of attention is always valued positively by workers, giving attention is assumed to be costly, at least above a certain level of attention. The reason is clear: Although giving some attention can evidently be pleasurable, it is also time-consuming, expensive, or perhaps even boresome at some point. In addition to these direct benefits and costs, we assume that social interaction creates altruistic feelings among colleagues. More specifically, we assume that receipt of attention leads to stronger feelings of altruism towards the giving agent. As we shall see, in equilibrium this gives rise to reciprocal behavior: When a worker has been treated kindly by a colleague, the worker cares more about his colleague's well-being, and adapts his future actions accordingly.

We obtain two main results. First, when the firm provides only individual performance incentives, too little social interaction takes place, implying lower than first-best profits for the firm. ${ }^{1}$ The reason is an externality problem. Each worker internalizes the benefits of giving attention to his co-workers in as far as he is altruistic towards his co-workers. Since people care more for themselves than they do for their colleagues, there is too little social interaction in equilibrium. This is costly to the firm: If the firm could induce workers to engage in more social interaction, workers' job satisfaction would be higher, allowing the firm to pay lower wages. Borzaga and Depedri (2005) have recently provided some evidence for such compensating wage differentials. They find that, in Italian non-profit organizations, satisfaction with colleagues is negatively associated with wages. Consistent with this, the field study by Hamilton et al. (2003) shows that quite a few workers of a Californian garment factory were willing to give up a substantial part of their salary so as to join team production, suggesting high non-pecuniary benefits from working in a team.

Second, the firm can promote social interaction among workers by including team incentives or relative incentives in the workers' contract. Consequently, the firm can achieve first-best profits by choosing the right mix of individual incentives and team or relative incentives. The intuition behind these results is as follows. Provision of team or relative incentives creates

\footnotetext{
${ }^{1}$ A similar result can be found in Itoh (1991b)'s study of social relations and incentive contracts, of which we became aware only after completing a first draft of this paper. In contrast to our model, workers in his model are not altruistic. Consequently, our results on optimal incentive contracts starkly differ from his.
} 
externalities among workers. Team incentives create positive effort externalities, implying underprovision of effort (free-riding); relative incentives create negative effort externalities, resulting in overprovision of effort from the perspective of the workers. These externality problems are less severe when workers are more altruistic towards each other. Hence, contracts with team or relative incentives strengthen workers' incentives to invest in coworker altruism. A natural way to do so is to engage in social interaction with colleagues. In other words, by deliberately creating an additional externality problem among workers through provision of either team or relative incentives, firms induce workers to resolve the initial externality problem of too little attention provision. Incentives for productive activities are restored through fine-tuning the level of individual incentives. Optimal contracts thus induce workers to exert first-best effort and to give first-best attention. Consequently, the firm achieves first-best profits.

Our model's predictions concerning the effect of team and relative incentives on the quality of co-worker relationships and workers' effort are supported by existing empirical findings. Firstly, there is evidence based on survey data. Burks et al. (2009) study social preferences of bicycle messengers in Switzerland and San Francisco and find that, compared to couriers in firms that pay for individual performance, couriers under team-based or hourly pay act more cooperatively in a prisoner's dilemma game and expect their co-workers to be more cooperative as well. ${ }^{2}$ Moreover, the paper provides some evidence that these differences in social preferences are endogenous to the employer's choice of compensation scheme. Likewise, Carpenter and Seki (2005) find among Japanese fishermen that those who pool their catch at the end of day are significantly more altruistic towards each other than those who organized themselves into groups that do not pool. Heywood et al. (2005) analyze data from the German Socioeconomic Panel and find evidence for the view that promotions and profit-sharing are alternative means of generating cooperation among workers. Their measure of cooperation is workers' response to the question "Do you get along with your colleagues?", which is close in spirit to the quality of interpersonal relationships that we focus on. Heywood and Wei (2006) examine data from the National Longitudinal Study of Youth (US) and find that co-worker satisfaction is significantly

\footnotetext{
${ }^{2}$ Unfortunately (for our purpose), the study pools the data for couriers under teambased and hourly pay. About $70 \%$ of the subjects in this pool receive team-based pay, the remaining $30 \%$ are on hourly pay.
} 
higher for workers who recently received a promotion. No such relation is found between co-worker satisfaction and individual performance pay, profitsharing, or the wage level.

A potential problem with evidence based on survey data is reversed causality: It may well be that high-quality co-worker relations are a determinant rather than the result of team or relative incentives. Field experiments circumvent this problem. Rotemberg (1994) discusses the famous Hawthorne experiments (Roethlisberger and Dickson 1939) where both workers' financial incentives and their opportunities for socializing were varied. The results suggest that team incentives encouraged friendship among workers and that this friendship was instrumental in raising output. More recently, Verbeke et al. (2009) ran a field experiment in a chain of shoe shops in the Netherlands. Team incentives for employees were introduced (on top of their hourly wages) in a random sample of the 125 shoe shops during a period of six weeks. After the experiment, a survey was held among employees. The results show positive effects of team incentives on social interaction among workers as well as on sales.

Lastly, the field study by Bandiera et al. (2005) compares fruit pickers' productivity under individual incentives and relative incentives. Their results strongly suggest that, when workers are paid on the basis of relative performance, they partially internalize the negative externality their effort imposes on others, especially when working alongside their friends. They do not find evidence for pure altruism, however. One reason for this could be that workers in their sample are hired on a daily basis, with no guarantee of further employment, giving little incentives to build up relationships.

This paper proceeds as follows. In the next section we give a brief overview of related literature and discuss how our paper contributes to it. Section 3 presents the model. In section 4 and 5 we examine the case of perfect contractibility and the case of non-contractible attention, respectively. Section 6 concludes.

\section{Related literature}

Our paper builds on Rotemberg's (1994) seminal analysis of human relations in the workplace. He argues that, when workers' actions are strategic complements and workers are paid as a function of joint output, they may rationally choose to become altruistic towards each other. Altruism serves 
as a commitment device to exert more effort, which - due to the strategic complementarity of workers' efforts - induces co-workers also to exert more effort. This is in the worker's narrow self-interest because of the free-rider problem inherent in team incentives.

We differ from his analysis in three important respects. First, while Rotemberg studies the effect of team incentives in isolation, we derive the properties of first-best contracts which are shown to consist of a mix of different types of incentives. Second, in contrast to Rotemberg, strategic complementarity between workers' productive actions is not a necessary condition for co-worker altruism to arise in our model. The reason is that we allow for a consumption benefit from social interaction at work, which is absent in Rotemberg. Last, and most important, we do not allow people to directly choose their altruistic feelings towards others. Instead, we assume that people may attempt to make others feel more altruistic towards them by being kind, showing attention, paying respect, offering favors, and so on. Thus, while as in Rotemberg an individual's altruistic feelings are endogenous in our model, the individual does not choose his feelings, but his feelings can be affected by other people's actions.

The way we model social interaction between workers and how it affects co-workers' altruism is close to the formalization of social ties in van Dijk and van Winden (1997). In their model, as in ours, social ties are represented by interdependent utility functions, where the weight assigned to the utility of the other agent depends on the history of interaction. ${ }^{3}$ The positive relationship between social interaction and the formation of social ties is supported by a large number of empirical studies in several branches of the social sciences. For example, Homans (1950) concludes from observations of workers at the Western Electric Company that "favourable sentiments increase as interaction increases" (p. 112). Additional support for this hypothesis can be found in Baumeister and Leary (1995), van Dijk, Sonnemans, and van Winden (2002), and Hays (1988). We differ from van Dijk and van Winden (1997) in the application, as they analyze the influence of social ties on the contribution to a public good. Further, we do not make the assumption that individuals are myopic with respect to the feelings of a colleague; instead workers may invest in social relationships for strategic reasons, e.g. to

\footnotetext{
${ }^{3}$ In a related approach by Bolle and Kritikos (2006), the altruism parameter is not defined as the weight assigned to the utility of the other agent, but as the marginal utility of a transfer to another agent. However, like in van Dijk and van Winden (1997), this altruism parameter depends on the past interaction with this agent.
} 
alleviate externality problems.

In another related approach, Cox, Friedman, and Gjerstad (2007) have developed a model where the marginal rate of substitution between an agent's own income and the income of another is influenced by actions of this other agent. In particular, an agent becomes more willing to pay for the income of the other agent, i.e. becomes more altruistic, if the other agent has been more generous to the former. Recently, Cox, Friedman and Sadiraj (2008) formulated a similar theory in a more general (nonparametric) framework of preferences over one's own and other people's payoffs. Both papers discuss results of existing laboratory experiments to validate the model. The results of these experiments indicate that people do become more altruistic in response to kind behavior.

The results of our analysis are in stark contrast to those of Lazear (1989) on sabotage in tournaments and of Kandel and Lazear (1992) on peer pressure in teams. These papers predict worse rather than better co-worker relations under relative or team incentives compared to individual incentives (see also Barron and Gjerde 1997). While we obviously do not deny that sabotage and peer pressure are relevant in many settings (see e.g. the experiences at Continental Airlines described in Knez and Simester 2001 and the study on 'dirty play' in professional soccer by Garicano and Palacios-Huerta 2005), the empirical evidence discussed in the previous section strongly suggests that opposite forces such as those studied in this paper can sometimes dominate.

The economics literature provides two alternative ways through which team-based pay may improve upon the work climate: by increasing workers' willingness to help each other and by reducing pay inequity at the workplace. Studies stressing workers' helping behavior include FitzRoy and Kraft (1986), Drago and Turnbull (1988), Itoh (1991a), Rob and Zemsky (2002), and Corneo and Rob (2003). A crucial difference between these studies and ours is that helping or cooperating is assumed productive in these studies, implying that there is a team-element in production, which is not necessarily the case in our model. Our paper can thus explain the prevalence of teambased pay and their positive effects on the work climate, even when there is little or no complementarity between workers' productive efforts. The same holds for studies which consider inequity-averse workers (see Bartling 2007, Demougin and Fluet 2006, Englmaier and Wambach 2005, Goel and Thakor 2006, Grund and Sliwka 2005, Itoh 2004, and Rey-Biel 2007). When workers dislike pay inequality, team incentives may outperform both individual and relative incentives, because team incentives generate little inequality of pay 
among workers. We differ from these studies in that workers are altruistic rather than inequity-averse, and that workers' altruism is endogenously determined. One implication is that - in line with the empirical evidence discussed in the previous section - the introduction of team-based incentives on top of flat wages increases the quality of co-worker relations in our model, while it is neutral in models of inequity aversion. Moreover, our results on the effects of relative incentives are also clearly different from those that arise when workers are inequity averse.

\section{The model}

We consider a profit-maximizing principal who employs two homogenous agents. ${ }^{4}$ Agents produce output by exerting effort. Effort of agent $i$ is denoted by $e_{i} \geq 0$. Total profits of the principal are:

$$
\pi=Q\left(e_{i}, e_{j}\right)-w_{i}-w_{j}
$$

where the production function $Q$ satisfies the Inada conditions with respect to all inputs, and $w_{i}$ denotes agent $i$ 's wage.

Agents care about three things: their wage, their cost of effort, and their net benefit from social interaction with colleagues. We model social interaction as an exchange of attention between agents. We assume that receiving attention is pleasurable, while giving attention is costly. ${ }^{5}$ The utility function of agent $i$ is:

$$
U_{i}=w_{i}-C\left(e_{i}, a_{i j}\right)+G\left(a_{j i}\right)+F\left(a_{j i}, U_{j}\right),
$$

where $a_{i j} \geq 0$ denotes the attention given by agent $i$ to agent $j$. The cost function $C$ is strictly convex and increasing in both arguments and satisfies the conditions $C(0,0)=0, C_{e}\left(0, a_{i j}\right)=0$, and $C_{a}\left(e_{i}, 0\right)=0$, where subscripts to functions denote partial derivatives. For simplicity, we assume

\footnotetext{
${ }^{4}$ Our results generalize to the case of an arbitrary number $n>2$ of agents. Details are available upon request.

${ }^{5}$ These assumptions are stronger than we need: They only need to hold at the margin in the optimum. For instance, allowing agents to enjoy giving attention up to some point would not change our results qualitatively.
} 
that $C_{e a}(\cdot)=0 .{ }^{6}$ Receiving attention generates two types of benefits to an agent, represented by the functions $G$ and $F$. First, we allow for a consumption benefit from attention, captured by the strictly concave and increasing function $G$, with $G_{a}(0)=+\infty .^{7}$ Second, we assume that receipt of attention leads to feelings of altruism for the giving agent, which increases the utility of the receiving agent when the giving agent has positive utility. This is captured by the function $F\left(a_{j i}, U_{j}\right)=\gamma a_{j i} U_{j}$, where $\gamma>0$. The specific functional form keeps the analysis tractable. To ensure an interior solution, we shall abstract from situations where $F_{u} \geq 1 .^{8}$ That is, agents always care more for themselves than for others. Last, note that the linearity of utility in income implies that the agent is risk-neutral.

The principal offers a contract to each agent that makes each agent at least as well off as his outside option $\bar{U}>0$. The principal can condition the agent's wage on the effort of the agent himself and also on the effort of his colleague $\left(w^{i}\left(e_{i}, e_{j}\right)\right)$. We shall speak of individual incentives when $w_{e_{i}}^{i}\left(e_{i}, e_{j}\right)>0$, of team incentives when $w_{e_{j}}^{i}\left(e_{i}, e_{j}\right)>0$, and of relative incentives when $w_{e_{j}}^{i}\left(e_{i}, e_{j}\right)<0$.

The timing of the game is as follows. In the first stage, the principal offers contracts to the agents, which they accept or reject. Next, agents decide simultaneously and independently how much attention to give to their co-worker. In the last stage, agents decide on the level of effort they exert. ${ }^{9}$

\footnotetext{
${ }^{6}$ Clearly, giving and receiving attention takes time and, hence, may increase worker's marginal cost of effort. On the other hand, as shown by some of the studies we discussed in the introduction, social contact with colleagues can reduce stress and increase job involvement. In practice, both of these arguments are likely to play a role, which may explain why the empirical evidence on the relation between worker cohesiveness and productivity is rather mixed (see Rotemberg 2006 for an overview). Itoh (1991b) provides a thorough analysis of the consequences of these kind of interdependencies between effort and attention provision in a closely related principal-multi-agent model.

${ }^{7}$ As will become clear, our results are qualitatively the same in the absence of a consumption benefit from receiving attention.

${ }^{8}$ Clearly, this is ensured when agents do not get a positive utility from $a \geq \frac{1}{\gamma}$. Note that it is easy to extend the function to allow for unconditional altruism or spite, e.g. $F\left(a_{j i}, U_{j}\right)=\gamma\left(a_{j i}+\phi\right) U_{j}$, where $\phi \neq 0$. This would not affect our results qualitatively except for situations where unconditional spite is very strong so that creation of co-worker altruism through social interaction is inefficient.

${ }^{9}$ Obviously, in the one-shot game that we study, the exact timing is important for the results. In a repeated setting where agents alternately give attention and provide effort, this would be much less of a concern. In such a setting, it is important that the agents have a finite horizon (e.g., retirement). In an infinite horizon model, first-best attention
} 


\section{Complete contract}

We start by studying the benchmark case where both effort and attention are contractible. Full contractibility implies that there is no reason to condition the wage on effort, and so an agent's compensation only consists of a base salary in this section. The principal's optimization problem is:

$$
\max _{e_{i}, e_{j}, a_{i j}, a_{j i}, w_{i}, w_{j}} Q\left(e_{i}, e_{j}\right)-w_{i}-w_{j}
$$

subject to the agents' participation constraints:

$$
\begin{aligned}
& w_{i}-C\left(e_{i}, a_{i j}\right)+G\left(a_{j i}\right)+F\left(a_{j i}, U_{j}\right) \geq \bar{U}, \\
& w_{j}-C\left(e_{j}, a_{j i}\right)+G\left(a_{i j}\right)+F\left(a_{i j}, U_{i}\right) \geq \bar{U} .
\end{aligned}
$$

The first-best levels of effort and attention are described in Proposition 1.

Proposition 1 The complete contract has the following properties:

1. Effort of each agent is strictly positive and equates the marginal benefits of effort to the principal with the marginal cost of effort to the agent: $Q_{e}(\cdot)=C_{e}(\cdot)$;

2. Attention by each agent is strictly positive and equates the receiving agent's marginal benefits with the giving agent's marginal cost of attention: $G_{a}(\cdot)+F_{a}(\cdot)=C_{a}(\cdot)$.

3. The wage makes each agent indifferent between accepting and rejecting the contract, given the first-best levels of effort and attention: $w=$ $\bar{U}+C(\cdot)-G(\cdot)-F(\cdot)$.

The proof is given in the appendix. As usual, the first-best contract induces agents to exert the level of effort that maximizes the joint surplus. The principal optimally includes a positive level of attention in the contract. Even though attention entails a cost for the giving agent, it produces a pleasant working environment for the receiving agent, which allows the principal to pay a lower wage.

may arise as equilibrium play without any contractual arrangements by the principal. 


\section{Incomplete contracts}

Next let us consider the more realistic case where workers' attention is not contractible; the principal cannot contract on workers' actions like showing interest in a colleague's personal life, treating colleagues with courtesy, or giving affective support. We keep the assumption of contractible effort. ${ }^{10}$ As we shall see, the principal finds it optimal to condition each agent's wage on the effort of both agents, $w\left(e_{i}, e_{j}\right)$. For convenience, we assume that the wage contract is linear in both $e_{i}$ and $e_{j}$. This is innocuous: As will become clear, the principal can not do better by offering nonlinear contracts. Let $w_{e_{i}}^{i}$ denote agent $i$ 's bonus per unit of effort provided by agent $i$ (representing individual incentives) and let $w_{e_{j}}^{i}$ denote agent $i$ 's bonus per unit of effort provided by agent $j$ (representing team or relative incentives). Further, let $s^{i}$ be agent $i$ 's base salary. We solve the maximization problem of the principal by backward induction, starting with the agent's choice of effort.

The first-order condition for agent $i$ 's optimal effort is described by:

$$
w_{e_{i}}^{i}(\cdot)+w_{e_{i}}^{j}(\cdot) F_{u_{j}}(\cdot)-C_{e_{i}}(\cdot)=0 .
$$

Effort has three effects on an agent's utility. First, when the principal gives individual incentives, the agent's wage increases with his effort. Second, when the principal has installed team incentives or relative incentives, agent $i$ 's effort choice affects agent $j$ 's income. Agent $i$ cares about this effect to the extent that he is altruistic towards his colleague. Last, there is a cost of providing effort. The optimal effort level equates these benefits and costs at the margin.

The comparative static effect of social interaction on the agent's effort is summarized in the following Lemma.

Lemma 1 Social interaction affects the agent's choice of effort as follows:

1. The effect of received attention on effort is described by:

$$
\frac{d e_{i}}{d a_{j i}}=\frac{F_{u_{j} a_{j i}}(\cdot) w_{e_{i}}^{j}(\cdot)}{C_{e_{i} e_{i}}(\cdot)},
$$

\footnotetext{
${ }^{10}$ None of the results change when effort is noncontractible as long as the principal can contract on a (noisy) signal of each agent's effort (e.g. output). Extending the model to allow for risk aversion of agents in the presence of noisy signals of effort does not affect our results qualitatively.
} 
implying that an agent's effort increases with received attention when the contract includes team incentives, while effort decreases with received attention when the contract includes relative incentives.

2. Attention given by agent $i$ has no effect on his effort:

$$
\frac{d e_{i}}{d a_{i j}}=0
$$

The first part of Lemma 1 echoes the results by Rotemberg (1994) and Bandiera et al. (2005) on the relation between co-worker altruism and effort. When workers care for one another, they partly take into account the externalities they impose on others. Compared to egoistic agents, this implies higher effort under team incentives and lower effort under relative incentives. As co-worker altruism increases with received attention, effort increases with attention under team incentives and it decreases with attention under relative incentives. The second part of Lemma 1 directly follows from the separability of effort cost and attention cost in the worker's utility function. Clearly, when effort and attention would be substitutes, agent's effort would decrease with attention given by the agent.

In the previous stage of the game, the agents decide independently on how much attention to give to their co-worker, taking into account the effect of their attention on effort in the next stage of the game. The first-order condition for agent's optimal attention is:

$$
\frac{d U_{i}}{d a_{i j}}=-C_{a_{i j}}(\cdot)+\frac{d U_{j}}{d a_{i j}} F_{u_{j}}(\cdot)+\frac{d e_{i}}{d a_{i j}} \frac{d U_{i}}{d e_{i}}+\frac{d e_{j}}{d a_{i j}} \frac{d U_{i}}{d e_{j}}=0 .
$$

Using the agents' first-order conditions for optimal effort (5), this can be simplified to:

$$
-C_{a_{i j}}(\cdot)+\frac{d U_{j}}{d a_{i j}} F_{u_{j}}(\cdot)+\frac{d e_{j}}{d a_{i j}} \frac{d U_{i}}{d e_{j}}=0 .
$$

Besides the direct cost of attention provision, giving attention has two effects on the agent's utility. First, when the agent has altruistic feelings towards his co-worker, he enjoys the increase in his co-worker's utility resulting from the receipt of attention. Differentiating (1), it follows that the increase in the co-worker's utility is:

$$
\frac{d U_{j}}{d a_{i j}}=G_{a_{i j}}(\cdot)+F_{a_{i j}}(\cdot)+F_{u_{i}}(\cdot) \frac{d U_{i}}{d a_{i j}}
$$


where the last term drops by the envelop theorem, using (7). Second, there is an indirect effect of attention provision through the co-worker's effort choice: By giving more attention, the agent induces the co-worker to change his level of effort in the next stage, which in turn affects the agent's utility. Differentiating (1) it follows that:

$$
\frac{d U_{i}}{d e_{j}}=w_{e_{j}}^{i}(\cdot)+F_{u_{j}}(\cdot) \frac{d U_{j}}{d e_{j}}=w_{e_{j}}^{i}(\cdot),
$$

where the last equality follows from applying the envelop theorem, using the first-order condition for optimal effort (5). Clearly, an agent's utility is only affected by his co-worker's effort when the contract includes team incentives or relative performance incentives. Similarly, we learned from Lemma 1 that a worker's effort is only affected by received attention when the contract has team or relative incentives. Taking these two results together, it follows that the last term of the first-order condition (8) is strictly positive when either team incentives or relative incentives are part of the agent's contract. That is, both team incentives and relative incentives create an additional marginal benefit from attention provision for each agent. This benefit stems from the effect of attention-giving on co-worker altruism and, hence, on effort. When the contract has team incentives, an agent's provision of attention induces the other agent to exert more effort in the next stage, which benefits the agent. Likewise, when the contract has relative incentives, the agent's provision of attention induces the other agent to exert less effort in the next stage, which again benefits the agent. Lemma 2 follows.

Lemma 2 Both team incentives and relative incentives promote social interaction among workers.

Intuitively, when team incentives are provided, agents invest in altruism so as to foster cooperation. When relative incentives are provided, agents invest in altruism so as to tame their colleague's eagerness to outperform.

Substituting (6), (9) and (10) into (8) gives agent $i$ 's first-order condition for optimal attention in a rewritten form:

$$
-C_{a_{i j}}(\cdot)+F_{u_{j}}(\cdot)\left[G_{a_{i j}}(\cdot)+F_{a_{i j}}(\cdot)\right]+\frac{F_{u_{i} a_{i j}}(\cdot) w_{e_{j}}^{i}(\cdot)}{C_{e_{j} e_{j}}(\cdot)} w_{e_{j}}^{i}(\cdot)=0 .
$$


Our next result follows immediately and is described in the following Proposition.

Proposition 2 When the principal does not provide team incentives or relative incentives $\left(w_{e_{j}}^{i}=0\right.$ for all $\left.i \neq j\right)$, there is too little social interaction in equilibrium.

Proposition 2 follows from a comparison of the first-order condition for attention (11) with first-best attention as described by Proposition 1 . In the absence of team or relative incentives, the last term of first-order condition (11) drops. Comparing with the first-best as described by Proposition 1, it follows that there is too little social interaction in any equilibrium where $F_{u}<1$, as we have imposed. That is: As agents care less about their coworker than about themselves, the benefits from attention provision are not fully internalized. Underprovision of attention results. Note that there exist multiple equilibria. First, an equilibrium exists where neither of the agents give attention. When an agent believes that the other agent will not give any attention, the second term of (11) is zero, implying that the agent only faces costs from attention provision (as reflected by the first term of (11)). Hence, given that an agent expects to receive no attention, it is optimal for him to give no attention as well. Second, depending on the exact shape of the functions, one or more equilibria with positive attention exist. When the function $G(\cdot)$, representing the consumption benefits from attention, is sufficiently concave, or the cost function $C(\cdot)$ is sufficiently convex in attention, there is a unique equilibrium with strictly positive attention. ${ }^{11}$ Anyway, since in all possible equilibria attention is described by (11), attention is always at a suboptimal level. As a result, the principal's profits are lower than first-best. ${ }^{12}$

Last, consider the principal's contract design problem, which is given by:

$$
\max _{w_{e_{i}}^{i}, w_{e_{j}}^{i}, w_{e_{j}}^{j}, w_{e_{i}}^{j}, s^{i}, s^{j}} Q\left(e_{i}, e_{j}\right)-\left(w_{e_{i}}^{i}+w_{e_{i}}^{j}\right) e_{i}-\left(w_{e_{j}}^{i}+w_{e_{j}}^{j}\right) e_{j}-s^{i}-s^{j},
$$

\footnotetext{
${ }^{11}$ The appendix describes the precise condition; it rules out that agent's responsiveness to received attention increases with received attention. In the remainder of this paper, we shall assume that this condition holds.

${ }^{12}$ Note that, since this result holds for any level of the cost of attention, companies that restrict their workplace policies to facilitating social interaction (that is, reducing agent's marginal cost of attention) will achieve lower than first-best profits.
} 
subject to the agents' participation constraints (3) and (4). First-best effort, attention, and profits are achieved by the incentive contract described in Proposition 3.

Proposition 3 When attention cannot be contracted, but effort can, the principal achieves first-best profits by offering an incentive contract consisting of a base salary, individual incentives, and team or relative incentives. Optimal individual incentives are described by:

$$
w_{e_{i}}^{i}=Q_{e_{i}}(\cdot)-F_{u_{j}}(\cdot) w_{e_{i}}^{j} \text { for } i \neq j,
$$

and optimal team or relative incentives are described by:

$$
w_{e_{j}}^{i}= \pm \sqrt{\frac{\left(1-F_{u_{j}}(\cdot)\right)\left[G_{a_{i}}(\cdot)+F_{a_{i}}(\cdot)\right] C_{e e}(\cdot)}{F_{u_{i} a_{i j}}(\cdot)}} \text { for } i \neq j,
$$

where all functions are evaluated at the first-best levels of effort and attention, as described by Proposition 1. The level of the base salary follows from the agents' participation constraints.

The proof is in the appendix. The principal can obtain maximum profits by including a mix of individual incentive pay and team or relative incentive pay in the contract. As we have seen in Lemma 2, team or relative incentives can be used to promote social interaction. In the optimum, the team incentives or relative incentives are chosen such that, given first-best effort, the agents provide first-best attention as described in Proposition 1. Next, the principal can ensure that agents exert first-best effort by adjusting the individual incentives. When attention provision is stimulated through team incentives, individual incentives are muted, since an agent enjoys the positive effect his effort has on his colleague's wage. With relative incentives, the effort of an agent negatively influences the utility of his co-worker, which in equilibrium is an additional cost of effort. Individual incentives therefore need to be adjusted upwards to restore efficient effort provision.

\section{Concluding remarks}

For many employees, social interaction with colleagues is one of the key determinants of job satisfaction. We have studied the influence of financial 
incentives for productive activities on the quality of co-worker relationships in a model where agents have endogenous other-regarding preferences. Following earlier work on the formation of social ties, we have assumed that the strength of a worker's altruistic feelings towards a colleague is increasing with the colleague's kindness towards the worker. We have seen that, absent team or relative incentives, workers do not invest enough in their relationships with their co-workers, as the benefits from relationship-building to the colleague are not fully internalized. This externality problem comes at a cost to the employer, as good co-worker relationships allow employers to attract and retain workers without paying high wages. We have shown that employers can stimulate social interaction among colleagues by providing either team incentives or relative incentives. These results are well in line with the empirical evidence discussed in the introduction.

We have deliberately kept the analysis as simple as possible. An interesting next step would be to study situations where the employer can only contract on team output, so that team incentives serve a dual role: promoting productive effort and stimulating social interaction. In such situations, too much social interaction may arise (as strong team incentives may be optimal to boost production, but as a side-effect create too much concern among workers to please each other). In response to this, employers may take actions so as to increase workers' cost of giving attention. Likewise, employers may not be so keen on encouraging social interaction when relative performance incentives are the sole instrument to promote effort. Other interesting extensions include heterogeneity in workers' social preferences and the sorting of different types of workers to firms offering different incentive schemes. Kosfeld and von Siemens (2007, 2009) make interesting steps in that direction. 


\section{Appendix}

\section{Proof of Proposition 1}

Let $\lambda_{i}$ denote the Lagrange-multiplier for the participation constraint of agent $i$. The first-order conditions are:

$$
\begin{aligned}
Q_{e_{i}}(\cdot)+\lambda_{i} \frac{d U_{i}}{d e_{i}}+\lambda_{j} \frac{d U_{j}}{d e_{i}}=0 ; & Q_{e_{j}}(\cdot)+\lambda_{i} \frac{d U_{i}}{d e_{j}}+\lambda_{j} \frac{d U_{j}}{d e_{j}}=0 ; \\
\lambda_{i} \frac{d U_{i}}{d a_{i j}}+\lambda_{j} \frac{d U_{j}}{d a_{i j}}=0 ; & \lambda_{i} \frac{d U_{i}}{d a_{j i}}+\lambda_{j} \frac{d U_{j}}{d a_{j i}}=0 ; \\
-1+\lambda_{i} \frac{d U_{i}}{d w_{i}}+\lambda_{j} \frac{d U_{j}}{d w_{i}}=0 ; & -1+\lambda_{i} \frac{d U_{i}}{d w_{j}}+\lambda_{j} \frac{d U_{j}}{d w_{j}}=0 ;
\end{aligned}
$$

and the two participation constraints. Using (A1) and (A3) and noting that

$$
\begin{gathered}
\frac{d U_{j}}{d e_{i}}=F_{u}(\cdot) \frac{d U_{i}}{d e_{i}}, \\
\frac{d U_{j}}{d w_{i}}=F_{u}(\cdot) \frac{d U_{i}}{d w_{i}}, \\
\frac{d U_{i}}{d e_{i}}\left(\frac{d U_{i}}{d w_{i}}\right)^{-1}=-C_{e}(\cdot),
\end{gathered}
$$

the first part of Proposition 1 follows. Substituting

$$
\begin{aligned}
\frac{d U_{i}}{d a_{i j}} & =-C_{a}(\cdot)+F_{u}(\cdot) \frac{d U_{j}}{d a_{i j}} \\
\frac{d U_{j}}{d a_{i j}} & =G_{a}(\cdot)+F_{a}(\cdot)+F_{u}(\cdot) \frac{d U_{i}}{d a_{i j}}
\end{aligned}
$$

into (A2) yields after successive substitution:

$$
\left[-C_{a}(\cdot)+G_{a}(\cdot)+F_{a}(\cdot)\right]\left[1+F_{u}(\cdot)+F_{u}^{2}(\cdot)+\ldots+F_{u}^{\infty}(\cdot)\right]=0,
$$

from which the second part of Proposition 1 follows. The third part follows from (A1) and (A3) which imply that $\lambda_{i}=\lambda_{j}>0$, and hence the participation constraints bind. 
Condition for unique equilibrium with strictly positive attention

Agent $i$ 's best-response curve has the following slope:

$$
\begin{gathered}
\frac{d a_{i j}}{d a_{j i}}=-\frac{d^{2} U_{i} / d a_{i j} d a_{j i}}{d^{2} U_{i} / d a_{i j}^{2}}=-\frac{F_{u_{j} a_{j i}}(\cdot)\left[G_{a_{i j}}(\cdot)+F_{a_{i j}}(\cdot)\right]+F_{u_{j}}(\cdot) F_{a_{i j} u_{i}}(\cdot) \frac{d U_{i}}{d a_{j i}}}{-C_{a_{i j} a_{i j}}(\cdot)+F_{u_{j}}(\cdot) G_{a_{i j} a_{i j}}(\cdot)} \\
\text { where } \frac{d U_{i}}{d a_{j i}}=G_{a_{j i}}(\cdot)+F_{a_{j i}}(\cdot)+F_{u_{j}} \frac{d U_{j}}{d a_{j i}}
\end{gathered}
$$

Note that at the origin the slope of the best-response curve is infinitely large, as $G_{a_{i j}}(0) \rightarrow+\infty$. Hence, to ensure that there is a unique equilibrium with strictly positive attention, it is sufficient that the best-response curve is strictly concave when $d a_{i j} / d a_{j i}>0$. The second derivative of the bestresponse curve is given by the following expression:

$$
\frac{d^{2} a_{i j}}{\left(d a_{j i}\right)^{2}}=-\frac{\left(d^{3} U_{i} / d a_{i j} d a_{j i}^{2}\right)\left(d^{2} U_{i} / d a_{i j}^{2}\right)-\left(d^{3} U_{i} / d a_{i j}^{2} d a_{j i}\right)\left(d^{2} U_{i} / d a_{i j} d a_{j i}\right)}{\left(d^{2} U_{i} / d a_{i j}^{2}\right)^{2}},
$$

where $d^{2} U_{i} / d a_{i j}^{2}$ and $d^{3} U_{i} / d a_{i j}^{2} d a_{j i}$ are always negative by the second-order condition and by the concavity of the $G(\cdot)$ function, respectively, and $d^{2} U_{i} / d a_{i j} d a_{j i}$ is always positive in the relevant area where $d a_{i j} / d a_{j i}>0$ (see (B1)). Hence, a sufficient (but not necessary) condition for the best-response function to be strictly concave when $d a_{i j} / d a_{j i}>0$ is:

$$
\begin{aligned}
& d^{3} U_{i} / d a_{i j} d a_{j i}^{2}=2 \gamma^{2}\left[-C_{a_{j i}}(\cdot)+\gamma a_{i j}\left(G_{a_{j i}}(\cdot)+\gamma U_{i}\right)\right]+ \\
& \gamma^{2} a_{j i}\left\{-C_{a_{j i} a_{j i}}(\cdot)+\gamma a_{i j}\left[G_{a_{j i} a_{j i}}(\cdot)+\gamma\left(d U_{i} / d a_{j i}\right)\right]\right\}<0
\end{aligned}
$$

which is satisfied when the $G(\cdot)$ function is sufficiently concave or the $C(\cdot)$ function is sufficiently convex in attention.

\section{Proof of Proposition 3}

The agent's choice of attention is described by first-order condition (11). Comparing with Proposition 1, to achieve first-best attention, the principal should set incentives such that the last two terms of (11) equal $G_{a}(\cdot)+F_{a}(\cdot)$, or:

$$
F_{u_{j}}(\cdot)\left[G_{a_{i j}}(\cdot)+F_{a_{i j}}(\cdot)\right]+\frac{F_{u_{i} a_{i j}}(\cdot) w_{e_{j}}^{i}}{C_{e_{j} e_{j}}(\cdot)} w_{e_{j}}^{i}=G_{a}(\cdot)+F_{a}(\cdot) .
$$

Solving for $w_{e_{j}}^{i}$ gives the expression for relative or team incentives in Proposition 3. The optimal level of individual incentives follows along similar lines, 
using first-order condition (5) and the expression for first-best effort in Proposition 1. Lastly, note that we do not need to be concerned about multiplicity of equilibria since, first, the equilibrium where both workers abstain from giving attention is no longer an equilibrium when $w_{e_{j}}^{i} \neq 0$, and, second, there exists only one equilibrium with strictly positive attention when condition (B3) holds, which is assumed. 


\section{References}

[1] Bandiera, Oriana, Iwan Barankay, and Imran Rasul (2005), Social Preferences and the Response to Incentives: Evidence from Personnel Data, Quarterly Journal of Economics, 120(3): 917-962.

[2] Barron, John M. and Kathy Paulson Gjerde (1997), Peer Pressure in an Agency Relationship, Journal of Labor Economics, 15(2): 234-254.

[3] Bartling, Björn (2007), Relative vs. Team Performance Evaluation with Inequity Averse Agents, Working Paper, University of Munich.

[4] Baumeister, Roy F., and Mark R. Leary (1995), The need to belong: desire for interpersonal attachments as a fundamental human motivation, Psychological Bulletin, 117(3): 497-529.

[5] Berman, Evan M., Jonathan P. West, and Maurice N. Richter, Jr. (2002), Workplace Relations: Friendship Patterns and Consequences (According to Managers), Public Administration Review, 62(2): 217230.

[6] Bolle, Friedel and Alexander Kritikos (2006), Reciprocity, Altruism, Solidarity: A Dynamic Model, Theory and Decision, 60(4): 371-394

[7] Borzaga, Carlo and Sara Depedri (2005), Interpersonal Relations and Job Satisfaction: Some Empirical Results, in: Benedetto Gui and Robert Sugden (Eds.), Economics and Social Interaction; Accounting for Interpersonal Relations, Cambridge: Cambridge University Press.

[8] Burks, Stephen, Jeffrey Carpenter, and Lorenz Goette (2009), Performance Pay and the Erosion of Worker Cooperation: Field Experimental Evidence, Journal of Economic Behavior and Organization, 70(3): 458469.

[9] Carpenter, Jeffrey and Erika Seki (2005), Do Social Preferences Increase Productivity? Field Experimental Evidence from Fishermen in Toyama Bay, Economic Inquiry, forthcoming.

[10] Cohen, Don and Laurence Prusak (2001), In Good Company: How Social Capital Makes Organizations Work, Harvard Business School Press. 
[11] Corneo, Giacomo and Rafael Rob (2003), Working in Public and Private Firms, Journal of Public Economics, 87(7-8): 1335-1352.

[12] Cox, James C., Daniel Friedman, and Steven Gjerstad (2007), A Tractable Model of Reciprocity and Fairness, Games and Economic Behavior, 59(1): 17-45

[13] Cox, James C., Daniel Friendman and Vjollca Sadiraj (2008), Revealed Altruism, Econometrica, 76(1): 31-69

[14] Demougin, Dominique and Claude Fluet (2006), Output and Wages with Inequality Averse Agents, Canadian Journal of Economics, 39(2): 399-413.

[15] Drago, Robert and Geoffrey K. Turnbull (1988), Individual versus Group Piece Rates under Team Technologies, Journal of the Japanese and International Economies, 2(1): 1-10.

[16] Ducharme, Lori J. and Jack K. Martin (2000), Unrewarding Work, Coworker Support, and Job Satisfaction, Work and Occupations, 27(2): 223-243.

[17] Echtelt, Patricia van, and Stella Hoff (2008), Wel of niet aan het werk: Achtergronden van het onbenut arbeidspotentieel onder werkenden, werklozen en arbeidsongeschikten, Den Haag: Social and Cultural Planning Office of the Netherlands.

[18] Englmaier, Florian and Achim Wambach (2005), Optimal Incentive Contracts under Inequity Aversion, IZA Discussion Paper No.1643.

[19] FitzRoy, Felix R. and Kornelius Kraft (1986), Profitability and ProfitSharing, Journal of Industrial Economics, 35(2): 113-130.

[20] Garicano, Luis and Ignacio Palacios-Huerta (2005), Sabotage in Tournaments: Making the Beautiful Game a Bit Less Beautiful, CEPR Discussion Paper No. 5231.

[21] Goel, Anand M. and Anjan V. Thakor (2006), Optimal Contracts when Agents Envy Each Other, Mimeo, DePaul University. 
[22] Grund, Christian and Dirk Sliwka (2005), Envy and Compassion in Tournaments, Journal of Economics and Management Strategy, 14(1): 187-207.

[23] Hamilton, Barton H., Jack A. Nickerson, and Hideo Owan (2003), Team Incentives and Worker Heterogeneity: An Empirical Analysis of the Impact of Teams on Productivity and Participation, Journal of Political Economy, 111(3): 465-497.

[24] Hays, R B. (1988), Friendship, in: S.W. Duck (Ed.), Handbook of Personal Relationships, London: Wiley.

[25] Heywood, John S., Uwe Jirjahn, and Georgi Tsertsvadze (2005), Getting along with Colleagues - Does Profit Sharing Help or Hurt?, Kyklos, 58(4): 557-573.

[26] Heywood, John S. and Xiangdong Wei (2006), Performance Pay and Job Satisfaction, Journal of Industrial Relations, 48(4): 523-540.

[27] Hodson, Randy (1997), Group Relations at Work, Work and Occupations, 24(4): 426-452.

[28] Homans, George C. (1950), The Human Group, New York: Harcourt, Brace, and World.

[29] Itoh, Hideshi (1991a), Incentives to Help in Multi-agent Situations, Econometrica, 59(3): 611-636.

[30] Itoh, Hideshi (1991b), Social Relations and Incentive Contracts, Kyoto University Economic Review, 41(1): 35-55.

[31] Itoh, Hideshi (2004), Moral hazard and other-regarding preferences, Japanese Economic Review, 55(1): 18-45.

[32] Kandel, Eugene and Edward P. Lazear (1992), Peer Pressure and Partnerships, Journal of Political Economy, 100(4): 801-817.

[33] Knez, Marc and Duncan Simester (2001), Firm-Wide Incentives and Mutual Monitoring at Continental Airlines, Journal of Labor Economics, 19(4): 743-772. 
[34] Kosfeld, Michael and Ferdinand von Siemens (2007), Competition, Cooperation, and Corporate Culture, IZA Discussion Paper No. 2927.

[35] Kosfeld, Michael and Ferdinand von Siemens (2009), Worker SelfSelection and the Profits from Cooperation, Journal of the European Economic Association, 7(2-3): 573-582.

[36] Krueger, Alan B. and David Schkade (2007), Sorting in the Labor Market: Do Gregarious Workers Flock to Interactive Jobs?, Journal of Human Resources, forthcoming.

[37] Lazear, Edward P. (1989), Pay Equality and Industrial Politics, Journal of Political Economy, 97(3): 561-580.

[38] Morrison, Rachel (2004), Informal Relationships in the Workplace: Associations with Job Satisfaction, Organisational Commitment and Turnover Intentions, New Zealand Journal of Psychology, 33(3): 114128.

[39] Mossholder, Kevin W., Randall P. Settoon, and Stephanie C. Henagan (2005), A Relational Perspective on Turnover: Examining Structural, Attitudinal, and Behavioral Predictors, Academy of Management Journal, 48(4): 607-618.

[40] Nielsen, Ivy K., Steve M. Jex, and Gary A. Adams (2000), Development and Validation of Scores on a Two-Dimensional Workplace Friendship Scale, Educational and Psychological Measurement, 60(4): 628-643.

[41] Price, James L. and Charles W. Mueller (1981), A Causal Model of Turnover for Nurses, Academy of Management Journal, 24(3): 543-565.

[42] Rey-Biel, Pedro (2007), Inequity Aversion and Team Incentives, Scandinavian Journal of Economics, 108(2): 297-320.

[43] Riordan, Christine M. and Rodger W. Griffeth (1995), The opportunity for friendship in the workplace: An underexplored construct, Journal of Business and Psychology, 10(2): 141-154.

[44] Rob, Rafael and Peter Zemsky (2002), Social Capital, Corporate Culture, and Incentive Intensity, RAND Journal of Economics, 33(2): 243257. 
[45] Roethlisberger, Fritz J. and William Dickson (1939), Management and the Worker, Cambridge, MA: Harvard University Press.

[46] Rotemberg, Julio J. (1994), Human Relations in the Workplace, Journal of Political Economy, 102(4): 684-717.

[47] Rotemberg, Julio J. (2006), Altruism, Reciprocity and Cooperation in the Workplace, in: S. Kolm and Jean Mercier Ythier (Eds.), Handbook on the Economics of Giving, Reciprocity and Altruism, vol. 2, pp. 13711407, Amsterdam: North-Holland.

[48] Shacklock, Kate H. (2005), Shall I stay?: The meaning of working to older workers in an organisational setting, Ph.D thesis, Griffith Business School, Griffith University.

[49] Van Dijk, Frans, Joep Sonnemans, and Frans van Winden (2002), Social ties in a public good experiment, Journal of Public Economics, 85(2): $275-299$.

[50] Van Dijk, Frans and Frans van Winden (1997), Dynamics of social ties and public good provision. Journal of Public Economics, 64(3): 323-341.

[51] Verbeke, Willem, Joeri Sol, Robert Dur, and Rick Bagozzi (2009), An Experimental Approach to Tournaments in a Retail Setting: Exploring Effects on Sales, Customer Service Levels, Social Capital and the Moderating Effect of Leadership Styles of Store Managers, mimeo, Erasmus University Rotterdam.

[52] Wagner, Rodd and James K. Harter (2006), 12: The Elements of Great Managing, Gallup Press. 